TANJA POLETAN JUGOVIĆ, Ph.D. ${ }^{1}$

E-mail: poletan@pfri.hr

DRAGAN ČIŠIĆ, Ph.D. ${ }^{1}$

(Corresponding author)

E-mail: dragan@pfri.hr

ROMAN GUMZEJ, Ph.D. ${ }^{2}$

(Corresponding author)

E-mail: roman.gumzej@um.si

${ }^{1}$ University of Rijeka, Faculty of Maritime Studies

Studentska 2, 51000 Rijeka, Croatia

2 University of Maribor, Faculty of Logistics

Mariborska cesta 7, 3000 Celje, Slovenia
Transport Logistics

Preliminary Communication

Submitted: 23 July 2018

Accepted: 25 Feb. 2019

\title{
SUPPLY CHAIN SERVICE QUALITY IMPROVEMENT BY E-MARKETPLACE AUTOMATION
}

\begin{abstract}
E-marketplaces have become an essential part of e-commerce. In our research, a decentralized agent-based e-marketplace platform was devised. Although there are significant agent-based supply chain models in the literature, measuring quality performance using agents is still a subject of investigation. In order to improve overall supply chain service quality by allowing companies' agents to evaluate the service quality of their partners through the history of their transactions, this article proposes a service quality agent model. The model is designed using MCDM tools to suit different approaches to supply chain management. Consequently, since more informed procurement decisions are taking place continuously and autonomously at each node of a supply chain, supply chain service quality is being improved along the whole supply chain. At the end, the service quality valuation model of the supply chain is empirically evaluated.
\end{abstract}

\section{KEY WORDS}

e-commerce; e-marketplace; agent-based systems; supply chain management; service quality;

\section{INTRODUCTION}

There is a wide consensus on the fact that it is not enough to improve the efficiency of an organization only internally, but it is also necessary to consider the competitiveness and efficiency of their whole supply chain [1]. Performance measurement and optimization play a vital role in improving the competitiveness of supply chains [2]. Moreover, with the rapidly developing world economy and global marketplaces, there has been a drastic increase in the pressure on organizations to find new ways to create and deliver value to customers through supply chain management. There has been a growing recognition of the importance of building relationships with customers for improvements in profitability, as well as serviceability and reduced costs throughout the supply chain [3].
Different authors [4] emphasize the importance of delivering superior total value to the customer in terms of promptness, cost, quality and flexibility rather than by focusing solely on promptness and cost. According to [5], service quality has been a major area of attraction for practitioners and researchers. Its proven relationship with improving business performance by lowering costs, increasing customer satisfaction, achieving customer loyalty and increasing profitability has further motivated both researchers and practitioners to explore this area.

The biggest problem that modern organizations face today is their inability to quickly adapt to changes dictated by fast-evolving supply chains. More specifically, organizations currently rely on various mechanisms to perform quality assessment of their partners and adapt their decision-making processes to improve their business performance. Hence, numerous research studies have dealt with the subject of service quality in supply chains and a consensus has been reached concerning a strong relationship among service quality and supply chain performance [6].

To achieve the desired global optimization throughout the entire supply chain, one must employ proper mechanisms to measure, monitor and control service quality through an interorganizational assessment system [7]. Such systems are sensibly implemented to identify opportunities for improved supply chain efficiency and competitiveness, to help understand how companies operating in supply chains affect each other's performance, to support the supply chain in satisfying consumer requirements and to assess the result of an implemented initiative [8]. As stated by [9] for collaborative networks, supply chains also have the need for decentralized operations where partners conduct their planning autonomously and only exchange a limited amount of information. A frequently proposed solution concept for this purpose are auction mechanisms and, more specifically, multi-agent systems. 
While many authors have worked on enhancing their supply chain operations using multi-agent technologies, none have focused on supply chain automation using a service quality assessment model, as defined in $[10,11]$.

According to [11], automation of supply chain management systems has long been a principal use of both academia and industry. In general, two approaches of service transformation in the digital era can be observed for efficient, service-quality-oriented supply chain management:

1) Centralized e-marketplace web portals, combining demand and supply in a temporally and spatially shared repository $[12,13]$, and

2) Decentralized, agent-based e-marketplaces with a yellow-page dictionary service and distributed network of temporally and spatially distributed agents of supply chain partners [14, 18-29].

E-marketplaces have become an essential part of e-commerce. The centralized website-based approach is being successfully exploited by companies not being connected by long-term contracts and direct e-business relations. Multiple such e-marketplaces have been established mostly being used by companies of a common industry to help them manage their supply chains.

Each of the above approaches focuses on enriching some aspects of traditional supply chain management information systems. The centralized e-marketplace approach facilitates interoperability amongst supply chain participants, regardless of their information system diversity. On the other hand, the participants are left with a limited degree of autonomy and without the capacity to adapt in a dynamic way to changing real-world situations. In case such situations arise, intelligent agents can provide the participating systems with a high degree of autonomy and dynamicity [14].

In contrast to centralized e-marketplace platforms, the agent-based approach is distributed and dynamic, and hence corresponds more closely with the natural behavior of the marketplace. In addition, the service quality within the entire supply chain of every contributing company is expected to gradually improve up- and downstream by utilizing the service of quality-oriented decision support and making increasingly informed decisions [15].

The academic literature shows that many authors have worked on enhancing their supply chain operations using multi-agent technologies. [16] has proposed a framework for the design of a multi-agent-based decision support system to manage disruptions and mitigation of risks in manufacturing supply chains. [17] has proposed a model that consists of seven agents that are working together to maintain supply, manufacture, inventory management and distribution. Each agent performs a specific function of the organization and shares the information with other agents. [18] presented an agent-based approach for supply chain event management problems, which can perform autonomous corrective control actions to minimize the effect of deviations in the plan that is currently being executed. [19] presented an agent-based framework for configuration of agile supply chains to demonstrate the application of agent technology for supply chain configuration based on a formal ontology that encodes the manufacturing capabilities of manufacturing suppliers. [20] worked on ontology-based negotiation knowledge using agent technologies and showed that, by using this method, negotiation behaviors would be more adaptive to various negotiation environments. [21] focused on the collaboration of demand, production and replenishment planning along with a supply chain, and proposed a multi-tier, negotiation-based mechanism supported by a multi-agent system. [22] presented a concept and application of a hybrid multi-agent approach to modeling and optimization of supply chain problems. They integrated mathematical programming and constraint logic programming using agent technology. [23] proposed SCOPE, a multi-agent modeling and simulation platform specifically designed to emulate and study complex supply chain systems. [25] used a case study to confirm that environmental uncertainty can be automatically reduced to a win-win mode demonstrating the self-adaptive property of the multi-agent supply chain systems. [26] proposed a multi-agent architecture which helps medium-sized enterprises to take an appropriate decision to mitigate uncertainty in the supply chain.

In the framework of our research, a decentralized agent-based e-marketplace platform has been devised [27]. As companies arise, they are registered with a yellow-page service corresponding to their line of business in general and their products in particular, as well as assigned agents that represent them in the e-marketplace. The yellow-page service, being used by all companies' agents on the e-marketplace, manages the routing of their requests for quotations. As companies may get closed, they are deregistered from this service. Once the quotations from supplier companies' agents have arrived, a selection and ordering procedures are conducted between a customer and its supplier agents. An automated selection decision is made based on service quality parameters from previous transactions and pricing information. The quotation of the selected supplier is confirmed and the rest are denied by the customer agent. The purchasing transaction is completed with the shipment confirmation from the chosen supplier.

The purpose of the automated selection procedure is to enhance decision-making with additional information and to consequently improve customer satisfaction and overall supply chain service quality by allowing companies' agents to evaluate the service quality of their partners through the history of their transactions. In the course of doing so, any transaction in progress 
is automatically subjected to a service quality evaluation, where the current transaction data, supplemented with historical data on previous transactions with the prospective supplier, are evaluated with the goal of meeting customers' needs the best way possible. Consequently, since more informed decisions are taking place continuously and autonomously within the whole e-marketplace, supply chain service quality is being improved along whole supply chains.

\section{GOAL}

The goal of this research is to investigate improvement of overall supply chain service quality by allocating companies' agents to assess the service quality of their associates throughout the history of their transactions. Therefore, since more informed decisions are taking place continuously and autonomously, supply chain service quality is being improved along the whole supply chain.

Although there are significant agent-based supply chain models in literature, measuring supply chain quality performance using agents is still a subject of investigation. There is a moderate number of articles concerning QoS and agents. Research mainly focuses on QoS of the agents themselves, as distribution of services in agents is reducing the computational load, affecting the quality of service of agents [28], or study decentralized mechanisms that assist in the negotiation of quantitative service-level agreements in multiagent systems [29].

This article deals with the mediation of service parameter quality for the supply chain and proposes models to quantitatively define distributed agent factors based on a different supply chain structure. Initially, the model parameters are described and decision procedure is presented, using multiple criteria decision analysis. As described criteria are conflicting, analytic hierarchy procedure (AHP) is used, not only to allow each company to modify parameters to suit their own requests but also to check consistency of their decisions. The evaluation procedure is presented, followed by an evaluation on a test sample.

\section{SERVICE QUALITY ASSESSMENT MODEL}

This research relies on the holistic approach to service quality assessment as defined in $[7,8]$. The main reasons for employing a holistic approach are in consequence of the otherwise identified absence of connection with a strategy, the lack of system thinking, in which a supply chain must be viewed as a whole entity, the lack of balanced approach integrating financial and non-financial measures, as well as the loss of supply chain context, thus encouraging local optimization. Based on the service quality assessment model, a novel multi-agent-based collaboration framework for interorganizational (supply chain) cooperation and ser- vice quality assessment that can perform supply chain management operations autonomously, according to the aforementioned goals, has been introduced.

Overall service quality assessment requires performance indicators that pertain to the service quality among supply chain partners (nodes) of a supply chain. To track service quality along supply chains, probes (defined by $q$ ) are placed between every pair of interlinked nodes. Since some of the performance indicators defined in [9] are qualitative, they are not suitable for automated service quality evaluation. Hence, only the quantitative service quality indicators shall form the basis for evaluation. We introduce the $q$ as a 4-tuple of service quality indicators $(C, T, D, P)$ representing service quality on every link between a chosen pair of the supply chain nodes. All mentioned service quality indicators were assigned an equation that best expresses their interrelations with the node's inputs (e.g. burden/load) as well as with other service quality criteria. Finally, overall service quality $(q)$ has been expressed as a normalized sum of these criteria.

Correctness represents the proportion of correctly completed transactions:

$C=\frac{c}{d}$

where $c$ represents the number of correctly fulfilled orders and $d$ the total number of orders.

Timeliness represents the proportion of timely completed transactions:

$T=\frac{t}{d}$

where $t$ represents the number of on-time fulfilled orders and $d$ the total number of orders. Timely fulfilled orders are those the processing time of which (tout-tin) is less than the time specified for delivery.

Dependability represents the sum of availability $(A)$ and reliability $(R)$, defined below:

$D=\frac{A+R}{2}$

Since the individual summands in Equation 3 are in the $(0.1)$ range, in order to normalize the result, it is divided by 2 .

Availability represents the proportion of time when a node is in a functioning condition (available to its customer's orders):

$A=1-\frac{M T T R}{M T T F}$

where $M T T F$ represents its average mean time to failure and MTTR its average mean time to repair (e.g. maintenance operations or other exceptional situations that prevent a node from responding immediately to an incoming request).

Reliability can be expressed as the opposite of a node's fault rate:

$R=1-F$ 
where $F$ represents the ratio of failures to fulfill requests (e.g. due to out-of-stock situations). Reliability is considered the ratio/percentage of cases when the observed process in a supply chain did not fail to complete.

The price of an item $(P)$ should be divided by the highest price $(\max \{P\})$ to render the price indicator for our service quality evaluation $(Q p)$, namely:

$$
Q p=1-\frac{P}{\max \{P\}}
$$

Finally, the overall service quality can be calculated as a normalized sum of these indicators:

$Q=\frac{C+T+D+Q p}{4}$

Since the individual summands are all in the (0.1) range, in order to normalize the result, it is divided by 4 . While fine-tuning the model, we might decide to ponder the individual summands, as indicated in [9]:

$Q=\frac{c C+t T+d D+p Q p}{c+t+d+p}$

A meaningful pondering may be different from application to application. However, considering supply chain management operations, a sensible option is consulting some experts and building an AHP model that represents the best consistent blend of their knowledge.

\subsection{Defining weights for model}

In our model, weights of four previously defined quality indicators have to be defined. As there are different supply chain production modes (push, pull and just in time (JIT)), weights of the quality indicators have to differ. It is clear that in JIT supply chain timeliness is more important than price and should consequently have greater weight.

The problem of defining weights, like any decision-making problem, usually affects tangible and intangible criteria, including quantitative and qualitative elements. Authors have used analytic hierarchy process (AHP), developed by Thomas L. Saaty in the 1970s, as a systematized technique for defining weights. [30, 40] AHP compares two indicators at a time, instead of comparing all indicators simultaneously. All indicators are pairwise assessed in order to derive their relative weights. Relative in this context means that indicator weights are calculated with respect to each other. Evaluation of the indicators is done by human experts and thus is by default incoherent. Pairwise comparison is local and when integrated into full model inconsistencies might occur. Paired comparison is formulated by distinguishing less dominant of two indicators and then scaling the priority between them by means of numerical scale for comparison developed by Saaty.
In our case, for each method five experts have done an evaluation. Comparisons have been arranged in a matrix and then the final matrix has been created using geometrical mean calculation.

From the Figures 1-4, one can see that different supply chain management methods lead to very different weights for indicators. While push and pull modes do not vary significantly, JIT mode has significantly different indicator weights. Differences in correctness weights are less than $1 \%$ for all modes, but

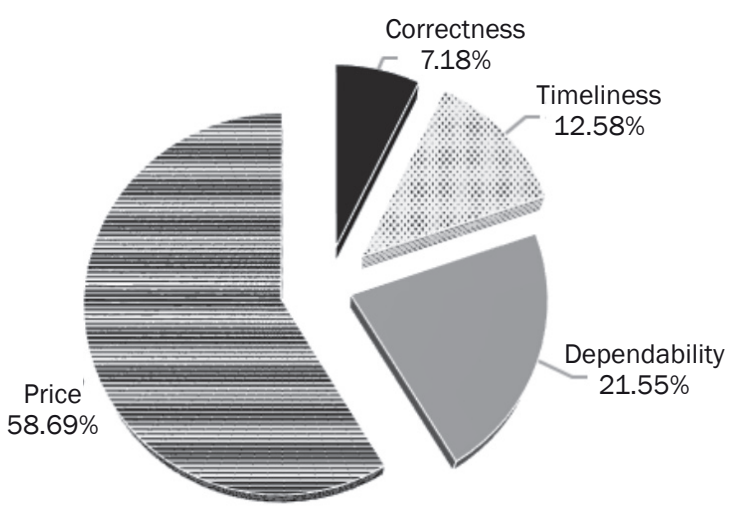

Figure 1 - Weights for indicators for push mode

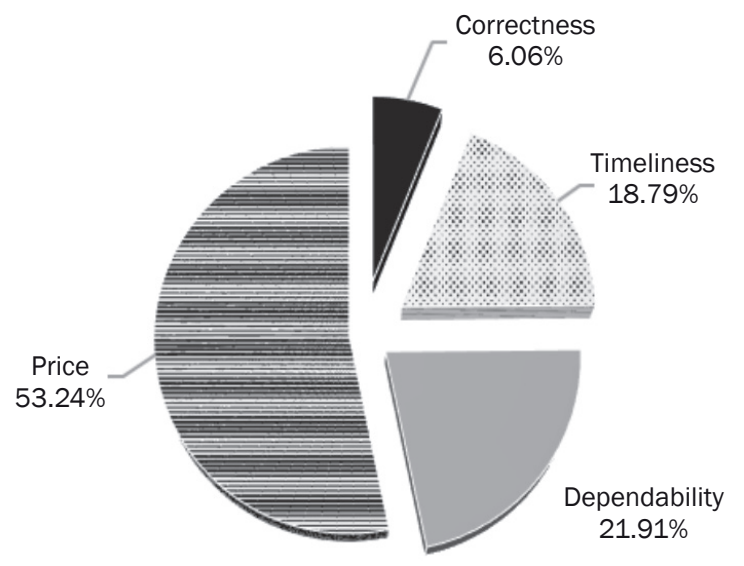

Figure 2 - Weights for indicators for pull mode

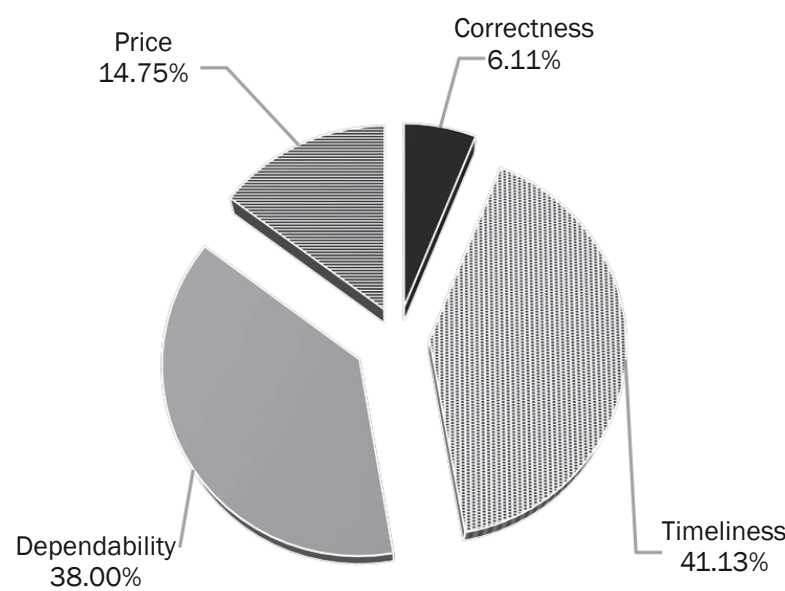

Figure 3 - Weights for indicators for JIT mode 


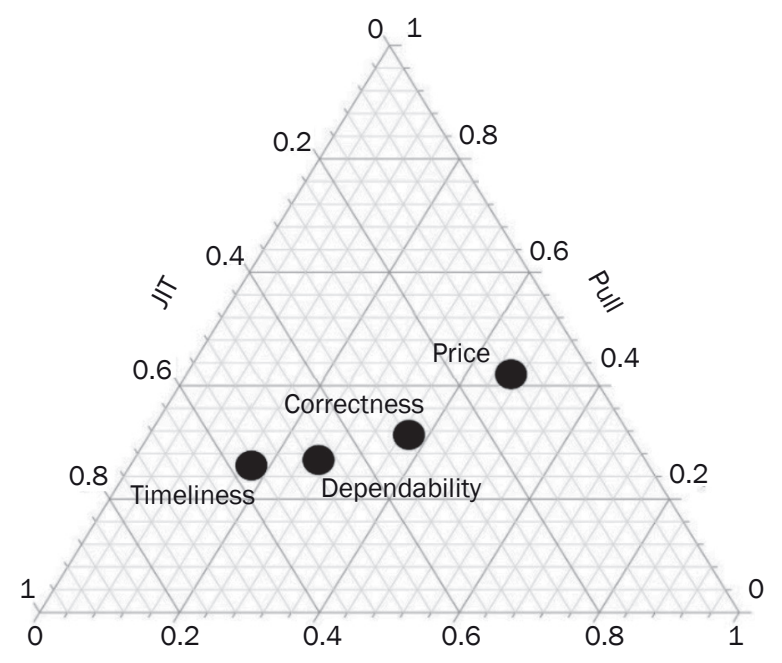

Push

Figure 4 - Comparison of results for all models

timeliness has a significant change of $6.21 \%$ for push vs. pull, $28.55 \%$ for push vs. JIT and $22.3 \%$ for pull vs JIT mode. The difference in dependability is 0.23 for comparison between push and pull mode but is bigger by $16 \%$ for JIT mode. Price variance is small (5.45\%) between push and pull modes but is significantly smaller (43.9\% and $38.49 \%$ respectively) when comparing JIT with push and pull mode.

As previously mentioned, because the numeric values are derived from the subjective judgment of individuals, it is difficult to prevent some inconsistencies in the final result. Saaty has proposed a calculation of the consistency ratio that comprises of the consistency index of calculated data compared with the consistency ratio of a random-like matrix. In AHP consistency ratio should not be larger than 0.1 . In practice, when dealing with experts not having knowledge of the AHP methodology, it is custom to treat the consistency ratio as a percentage, defining that inconsistency should not supersede $10 \%$. Shown in a similar manner, inconsistencies for push, pull and JIT mode are 5.11\%, $1.55 \%$ and $0.88 \%$ respectively.

Finally, for the purpose of our model, the combination of the defined three supply chain modes is calculated, including correctness, timeliness, dependability and price values $(6.95 \%, 23.77 \%, 29 \%$ and $40.28 \%$, respectively). Consistency index is 0.0043 or $0.43 \%$.

\subsection{Bayesian model}

Since our evaluation model is used incrementally and with every transaction, our knowledge base is updated and we may use it to construct a Bayesian model.
In the design of our experiment, sequential analysis techniques have been used, including the outcomes of earlier scenarios in the design of the next scenario. This has been achieved by updating "beliefs" throughout the prior and posterior distributions.

After every supply chain, transaction between any pair of the observed supply chain nodes is processed, service quality gain is recalculated for a specific supply chain node involved in the transaction and any future selection decisions are made based on the highest value of the service quality gain indicator:

$Q G_{i, j}=Q G_{i, j-1}+\frac{Q}{n_{i}}$

where $i$ represents the corresponding supplier, $Q G$ its service quality gain and $j$ its instance where the current transaction $Q$ is added to the corresponding $Q G$ and $n_{i}$ represents the total number of transactions of the corresponding supplier node.

\section{EVALUATION}

Let's consider a concrete ordering process use case. There are two distinct scenarios that are being observed here:

1) The customer decides to buy an item from a supplier based only on the price of the item. Here, the supplier's agent with the lowest price is chosen overall $Q$ is calculated solely based on $Q p$.

2) The customer decides to buy an item from suppliers' agents based on price and the service quality they offer. Here, all service quality criteria defined above are taken into consideration - overall $Q$ is measured based on $C, D, T$ and $Q p$.

The first scenario is obvious. The minimum price tag is chosen as best $Q p$. For the purpose of comparison, the offered prices are divided by the maximum price in order to normalize the indicator.

In the second scenario, one needs to consider the service quality of every supplier. The correctness indicator represents the proportion of correctly fulfilled orders, based on the supplier's records. If the number of correctly fulfilled orders $(c)$ by the supplier is 38 and the total number of orders $(d)$ is 47 , then the correctness indicator $(C)$ of the supplier is $81 \%(0.81)$.

The timeliness indicator represents the proportion of orders completed on time. If the number of timely fulfilled orders $(t)$ to our supplier is 40 , the timeliness (T) indicator of the supplier is $85 \%(0.85)$, based on the same number of orders $(d)$.

According to Equation 3, the dependability $(D)$ indicator is calculated as an average value of its availability $(A)$ and reliability $(R)$ indicators:

- If the node was down (unable to serve our requests) in $81 \%$ of the cases, its availability is $19 \%(A=0.19)$.

- If the node was unable to deliver the ordered amount of items in $6 \%$ of the cases, its reliability is 94\% $(R=0.94)$. 
Hence, in our case, the dependability indicator $(D)$ of the supplier is $56 \%(D=0.56)$.

Finally, the price indicator for the item is calculated by dividing the price, given by our supplier (e.g. EUR 53.27), with the maximum price from all suppliers (e.g. 161.42), which renders 0.66 as our $Q p$ indicator.

With all the service quality indicators known, the overall $Q$ indicator of the supplier can now be calculated (0.72).

Taking the two cases into consideration, our conclusion is the following. If the customer decides to buy the item from the supplier, the only bidder, based solely on price, the $Q$ would be 1-53.27/53.27=0. In case there were two suppliers and the price tag of the other supplier was 161.42, its $Q$ would be $1-53.27 / 161.42=0.66$, whereas the other supplier's $Q$ would be 0 .

In contrast, if all the service quality criteria were taken into consideration, then the $Q$ of the first supplier would be 0.72. If we knew nothing about the other supplier, then it would obviously win; however, if the second supplier was best in its field (with its other service quality indicators close to 1 ), its $Q$ would be 0.75 or higher and hence the second supplier would be chosen, despite the higher price tag.

Hence, by taking $C, T$ and $D$ indicators into consideration, the customer makes an informed decision based on the information on how its potential suppliers have been performing in the past, i.e., how many times:

- the correct product has been shipped to a customer,

- the delivery has been on time,

- the supplier has been available and reliable in fulfilling customer's orders.

If the decisions on the purchase were made solely based on the price of the product, the customer's risk of getting the wrong item or getting the right item too late would be much higher and could lead to dissatisfaction of its customers and consequently to lower overall service quality within its supply chain.

\subsection{Statistical evaluation}

In our example, we have generated 100 transactions and split transaction objects evenly among our 5 supplier agent objects (Agents 1 to 5), being members of our customer agent's (Agent) supply chain.

Our experiment is based on 100 sequential randomly generated samples of service quality entries corresponding with random orders between the agents within our supply chain. Every entry is associated with a single transaction between our customer agent and one of the five supplier agents. Since we cannot make any assumptions on the total number of orders, we have chosen a random number from the (1:1000) interval for this indicator. An equally random number from the (0.1) interval has been chosen as the nodes' failure rate. To calculate the prices, we have chosen random numbers from the $(1: 100)$ interval, rendering a normal (Gaussian) distribution of prices with an average value of 50 and standard deviation of 25.

The results of performing our experiment (Figure 5) are presented graphically in Figures 6 and 7 .

In Figure 6, a comparison between the overall effects of different service quality indicators on overall supply chain service quality is being presented. Specifically, the difference between the single value "best price" quality policy $Q(P)$ and the "best service quality" composite quality policy $Q(C, T, D, P)$ is emphasized.

In Figure 7, the individual transaction data are considered. Here, the actual and chosen suppliers are outlined together with the dynamics of growth of the individual service quality gains of the suppliers.

$C$ - correctness

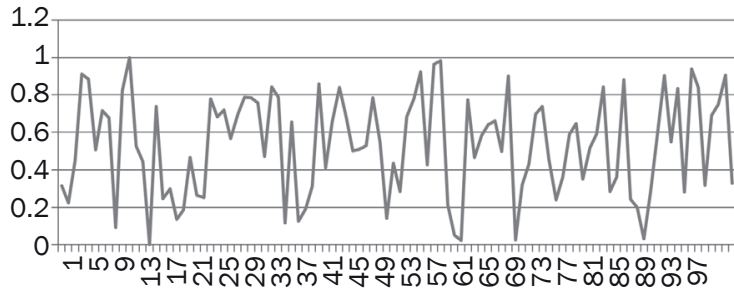

$T$ - timeliness

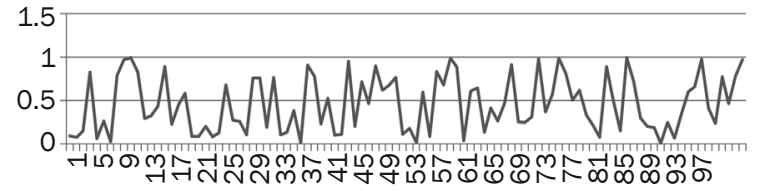

$D$ - dependability

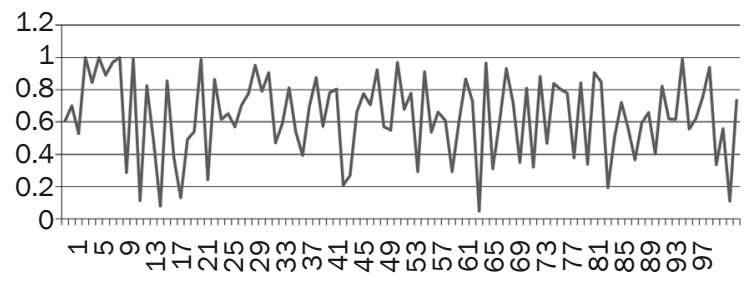

$P$ - price

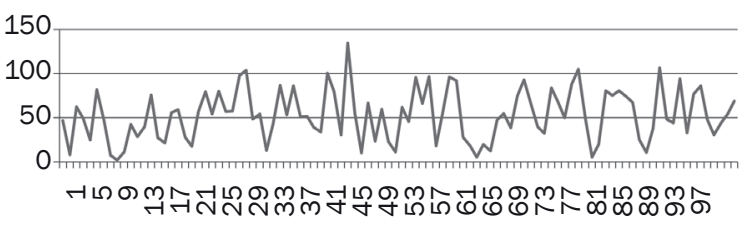

Figure 5 - Service quality indicators values for our transactions 


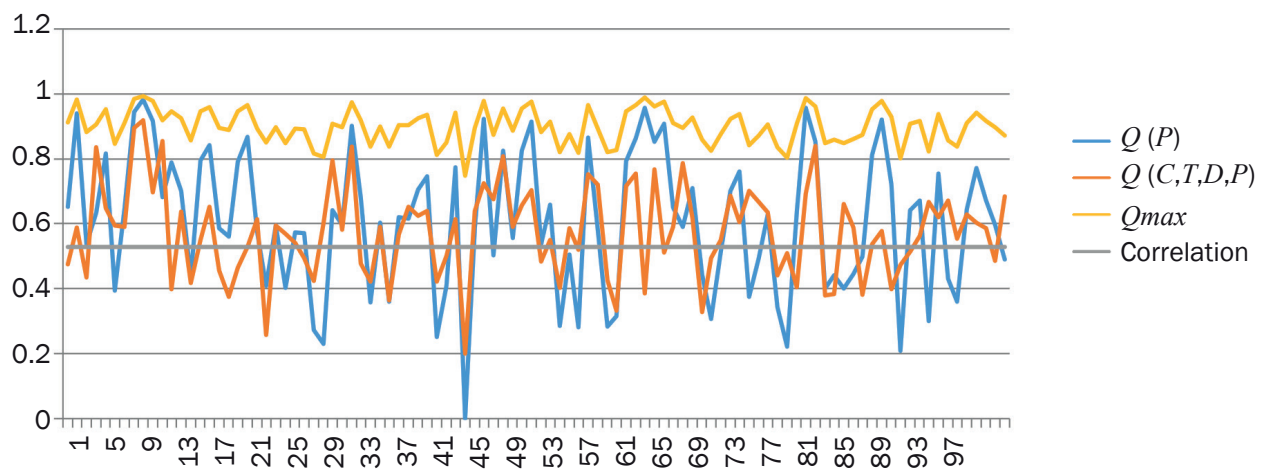

Figure 6 - Comparison between service quality evaluation models

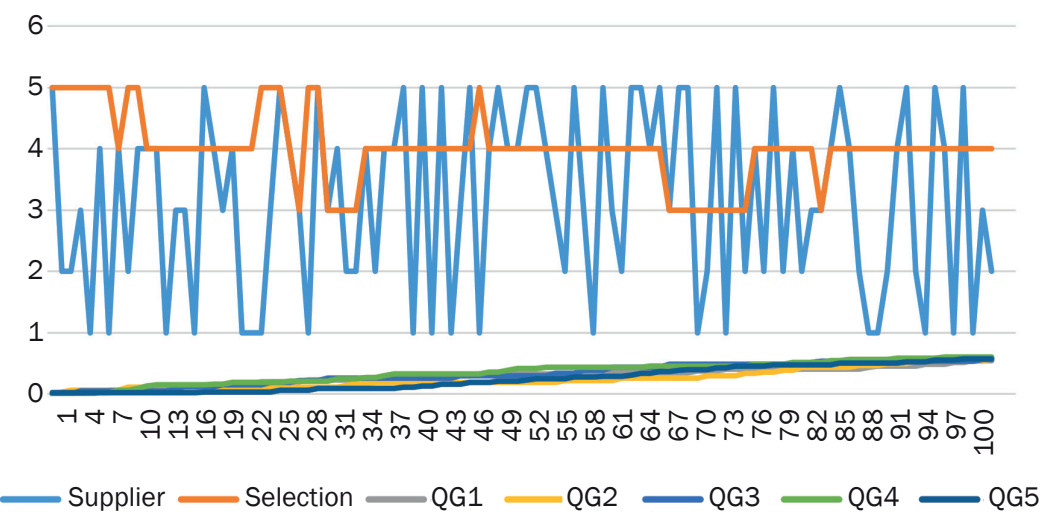

Figure 7 - Selection vs. QoS gain by the supplier (1-5)

\subsection{Analysis}

In our experiment, we have tested the combined effect of QoS oriented decision-making within SCM based on experience from previously performed orders.

We can see that decisions made solely based on the price $(P)$ criterion could be misleading in many cases. On the other hand, decisions made only based on previous QoS could also be misleading. Hence, the introduction of the Bayesian reasoning, where every QoS represents a gain (positive and negative) to the current QoS indicators, offers an opportunity to handle the dynamics of our model. Hence, the combination of both methods offers us a better reasoning in SCM decision-making considering also the non-price criterions in every decision made to the best of one's knowledge.

One can observe that the composite quality values better resemble the optimum $Q \max$ curve being based on maximum $C, T, D$ and current $P$ values. $Q(C, T$, $D, P)$ oscillations are smaller as opposed to the $Q(P)$ curve, which still resembles the optimum curve, however, its oscillations are much higher. From the correlation between $Q(\mathrm{P})$ and $Q(C, T, D, P)$, one can deduce that some $50 \%$ of supplier selection decision information originates from non-price related indicators.

\section{RESULTS}

From our analysis, we can conclude that our Bayesian service quality evaluation model generally has a positive effect on overall supply chain service quality of the observed supply chain. Considering the values of our quality indicators $Q(P)$ and $Q(C, T, D, P)$, we can claim that the decision model based on composite service quality evaluation would positively influence SCM business logic for two reasons:

1) Composite service quality values prevent us from making quick uninformed decisions based solely on price variations;

2) When considering the supply chain as a whole, the ordering process based on composite service quality evaluation would result in its lower oscillations. Since they usually represent some extraordinary events and offer us little information on their background, high oscillations in SCM are generally considered negative.

In other words, our service quality assessment model is feasible and better suited for automated decision-making in our e-marketplace platform [27] than solely price-based decision-making. When introduced as a global e-marketplace platform with automated QoS-oriented reasoning, it would render an objective SCM broker to all participating partners. 
Furthermore, in classic marketplaces, economic theory leads to monopoly [31] or even to the market breakdown, because either only one (the cheapest) supplier will survive or all the suppliers will be ruined due to severe competition. In order to prevent this situation, suppliers are continuously changing prices in order to significantly increase search costs and concede survivability of the e-marketplace. In the supply chains this is still not occurring, even though the current occurrences in different business environments are supporting this fact (for example UBER and taxi marketplace, or recently Alibaba One Touch, Maersk and CMA CGM) [32,33]. When e-marketplaces agents are added in equation, then there is no theoretical mode to prevent monopoly if price is the only factor of choice of suppliers.

The proposed model is specifically designed to handle the problems in cases where agents are selecting suppliers based on the lowest price, taking into account additional quality of service aspects. Although there are several papers dealing with agents and quality of service, they have been used in communication environments or factors have been created using machine learning services embedded in agents. This research shows that there are different weights for the service indicators that should be used in different supply chain and production systems. Weights for push production system price are the main factor, while in other supply chain modes its value is declining considerably. The AHP method is used for initial evaluation of weights for the quality of service indicators, because it incorporates an efficient procedure for checking the consistency of the assessments. Starting from assessed values, agents are using Bayesian method for fine tuning of the indicator weights, allowing fast adjustment to real and desirable values, preventing either extensive oscillations in system or even theoretical marketplace breakdown.

\section{CONCLUSION}

In supply chain management two approaches to service transformation in the digital era can be observed for efficient, service quality-oriented supply chain management:

1) Centralized e-marketplace web portals, combining demand and supply in a temporally and spatially shared repository;

2) Decentralized, agent-based e-marketplaces with a yellow-page dictionary service and distributed network of temporally and spatially distributed agents of supply chain partners.

In our research, the latter approach has been chosen, since it resembles the natural behavior of supply chain nodes which: appear, register their services, handle inquiries and orders, and establish their own service quality-based supply chains on the supply chain network with their partners.

In the article, the structure, behavior and communication models of the proposed multi-agent framework with a service quality-oriented assessment model for collaboration within supply chains have been presented. A basic underlying e-commerce ontology has been introduced. The method for assessing the service quality-based and its adoption into supply chain management operations has been presented. As a conclusion, the service-quality-based supply chain management model has been statistically evaluated against randomly created e-commerce transactions.

The most important finding of our research is that the service quality decision model adds more than $50 \%$ of information when choosing a supply chain partner for collaboration on the customer side (i.e., as opposed to decisions based solely on product/service price).

Hence, we may conclude that by adopting our framework the service quality within supply chains could be significantly improved. Since supply chain partners do not need to disclose any additional information on their business transactions than they already do in their current SCM operations, there is also no reason for rejection of the proposed solution due to information hiding. With the advent and deployment of the blockchain technology, its benefits are also being introduced into decentralized electronic marketplaces, providing for their strengthened confidentiality, integrity and availability [30].

\section{Dr. SC. TANJA POLETAN JUGOVIĆ ${ }^{1}$ \\ E-mail: poletan@pfri.hr \\ Dr. sc. DRAGAN ČIŠIĆ ${ }^{1}$ \\ E-mail: dragan@pfri.hr \\ Dr. Sc. ROMAN GUMZEJ² \\ E-mail: roman.gumzej@um.si \\ ${ }^{1}$ Sveučilište u Rijeci, Pomorski Fakultet Studentska 2, 51000 Rijeka, Hrvatska \\ 2 Univerza v Mariboru, Fakulteta za logistiku \\ Mariborska cesta 7, 3000 Celje, Slovenija}

\section{POBOLŠANJE KVALITETE USLUGA DOBAVNOG LANCA AUTOMATIZACIJOM E-TRŽIŠTA}

\section{SAŽETAK}

E-tržišta postala su bitan dio e-poslovanja. U našem istraživanju osmišljena je decentralizirana platforma za e-tržište utemeljena na agentima. lako u literaturi postoje značajni modeli dobavnog lanca koji se temelje na agentima, mjerenje efektivnosti agenata uporabom performansa kvalitete $i$ dalje je predmet istraživanja. U cilju poboljšanja kvalitete usluga dobavnog lanca uporabom agenata koji procjenjuju kvalitetu usluge tvrtki partnera kroz povijest transakcija, ovaj članak predlaže model agenta kvalitete usluge. Model je dizajniran pomoću MCDM alata koji 
odgovaraju različitim pristupima upravljanju dobavnim lancem. Slijedom toga, budući da se sveobuhvatnije odluke o nabavi odvijaju kontinuirano i autonomno u svakom čvoru, kvaliteta usluga poboljšava se duž cijelog dobavnog lanca. Na kraju se empirijski vrednuje model vrednovanja kvalitete usluga dobavnog lanca.

\section{KLUČNE RIJEČI}

e-poslovanje; e-tržište; sustavi temeljeni na agentima; upravljanje dobavnim lancem; kvaliteta usluge;

\section{REFERENCES}

[1] Christopher M. Logistics and supply chain management creating value-added networks. Harlow, England, New York: FT Prentice Hall; 2005.

[2] Zhang W, Reimann M. Towards a multi-objective performance assessment and optimization model of a two-echelon supply chain using SCOR metrics. Central European Journal of Operations Research. 2014;22(4): 591-622.

[3] Niraj R, Gupta M, Narasimhan C. Customer profitability in a supply chain. Journal of Marketing. 2001;65(3): 1-16.

[4] Ketchen DJ, et al. Best value supply chains: A key competitive weapon for the 21st century. Business Horizons. 2008;51(3): 235-243.

[5] Seth N, Deshmukh S, Vrat P. A framework for measurement of quality of service in supply chains. Supply Chain Management: An International Journal. 2006;11(1): 82-94.

[6] Chow G, Heaver TD, Henriksson LE. Logistics performance: definition and measurement. International Journal of Physical Distribution \& Logistics Management. 1994;24(1): 17-28.

[7] Sahay B, et al. A conceptual model for quality of service in the supply chain. International Journal of Physical Distribution \& Logistics Management. 2006;36(7): 547-575.

[8] Lyons A, et al. Supply Chain Performance Measurement. In: Customer-Driven Supply Chains. Springer London; 2012. p. 133-148.

[9] Mes M, van der Heijden M, Schuur P. Interaction between intelligent agent strategies for real-time transportation planning. Central European Journal of Operations Research. 2013;21(2): 337-358.

[10] Gumzej R, Gajšek B. Introducing quality of service criteria into supply chain management for excellence. In: Luo Z. Technological Solutions for Modern Logistics and Supply Chain Management; 2013. p. 70-86.

[11] Gumzej R, Sukjit P, Unger H. Modelling Overlay Networks for Autonomous Supply Chain Systems. Logistics \& Sustainable Transport. 2012;3(2).

[12] Rashad W, Gumzej R. The Information Technology in Supply Chain Integration: Case Study of Reda Chemicals with Elemica. International Journal of Supply Chain Management. 2014;3(1).

[13] Kim K, Paulson BC Jr, Petrie CJ Jr. Agent based electronic markets for project supply chain coordination. Proceedings of the AAAI-OO Workshop on Knowledge-Based Electronic Markets, USA, 1999.

[14] Pal K, Karakostas B. A multi agent-based service framework for supply chain management. Procedia Computer Science. 2014;32: 53-60.

[15] Evangelista P, Mogre R, Perego A, Raspagliesi A, Sweeney E. A survey based analysis of IT adoption and 3PLs' performance. Supply Chain Management: An International Journal. 2012;17(2): 172-186.

[16] Kovalchuk Y. A Multi-agent decision support system for supply chain management. PhD thesis. University of Essex; 2009.

[17] Rady HA. Multi-agent system for negotiation in a collaborative supply chain management. International Journal of Video \& Image Processing and Network Security. 2011;11(5).

[18] Bearzotti LA, Salomone E, Chiotti OJ. An autonomous multi-agent approach to supply chain event management. International Journal of Production Economics. 2012;135(1): 468-478.

[19] Ameri F, McArthur C. A multi-agent system for autonomous supply chain configuration. The International Journal of Advanced Manufacturing Technology. 2013;66(5-8): 1097-1112.

[20] Wang G, Wong T, Wang X. An ontology based approach to organize multi-agent assisted supply chain negotiations. Computers \& Industrial Engineering. 2013;65(1): 2-15.

[21] Hernández JE, et al. Collaborative planning in multi-tier supply chains supported by a negotiation-based mechanism and multi-agent system. Group Decision and Negotiation. 2014;23(2): 235-269.

[22] Sitek P, Nielsen IE, Wikarek J. A hybrid multi-agent approach to the solving supply chain problems. Procedia Computer Science. 2014;35: 1557-1566.

[23] Domínguez R, Cannella S, Framinan JM. SCOPE: A Multi-Agent system tool for supply chain network analysis. EUROCON 2015-International Conference on Computer as a Tool, IEEE. IEEE; 2015.

[24] Dominguez R, et al. Using multi-agent systems to explore information sharing in arborescent supply chain networks. Proceedings of 2013 International Conference on Industrial Engineering and Systems Management (IESM). IEEE; 2013.

[25] Fu J, Fu Y. An adaptive multi-agent system for cost collaborative management in supply chains. Engineering Applications of Artificial Intelligence. 2015;44: 91100.

[26] Kumari S, et al. A multi-agent architecture for outsourcing SMEs manufacturing supply chain. Robotics and Computer-Integrated Manufacturing. 2015;36: 36-44.

[27] Gumzej R, Čišić D. Decentralized Agent-based Electronic Marketplace Supply Chain Ecosystem. Scientific Journal of Maritime Research. 2018;32: 21-27.

[28] Román Gallego JÁ, Rodríguez González S. Improvement in the distribution of services in multi-agent systems with SCODA. ADCAIJ: Advances in Distributed Computing and Artificial Intelligence Journal. 2015;4(3): 31-46

[29] Gnanasambandam S-N. Performance modeling and resource allocation for adaptive agent-based systems. PhD thesis. The Pennsylvania State University; 2007.

[30] Saaty TL. Relative Measurement and its Generalization in Decision Making: Why Pairwise Comparisons are Central in Mathematics for the Measurement of Intangible Factors - The Analytic Hierarchy/Network 
Process. Review of the Royal Academy of Exact, Physical and Natural Sciences, Series A: Mathematics (RACSAM). 2008;102(2): 251-318. Available from: doi:10.1007/bf03191825 [Accessed 22 Dec 2008].

[31] Weyl EG. A price theory of multisided platforms. The American Economic Review. 2010;100(4): 16421672.

[32] Signature of a digital cooperation between CMA CGM and Alibaba OneTouch. Available from: https://www. cma-cgm.com/news/1496/signature-of-a-digital-cooperation-between-cma-cgm-and-alibaba-onetouch [Accessed on March 2018].

[33] Alibaba Is Teaming Up with This Shipping Giant. Available from: http://fortune.com/2017/01/04/alibabamaersk-shipping-partnership-onetouch/ [Accessed on March 2018].

[34] Giannakis M, Louis M. A multi-agent based framework for supply chain risk management. Journal of Purchasing and Supply Management. 2011;17(1): 23-31.
[35] Bellifemine FL, Caire G, Greenwood D. Developing multi-agent systems with JADE. Vol. 7. John Wiley \& Sons; 2007.

[36] Russell S, Norvig P. Artificial Intelligence: A modern approach. Englewood Cliffs: Prentice-Hall; 1995.

[37] Fensel D. Ontologies: A Silver Bullet for Knowledge Management and Electronic Commerce. Berlin, Heidelberg: Springer; 2001. p. 11-18.

[38] Bellifemine F, Poggi A, Rimassa G. Developing multiagent systems with a FIPA-compliant agent framework. Software-Practice and Experience. 2001;31(2): 103-128.

[39] Subramanian H. Decentralized Blockchain-based Electronic Marketplaces. Communications of the ACM. 2018;61(1): 78-84.

[40] Saaty TL, Kirti P. Group Decision Making: Drawing out and Reconciling Differences. Pittsburgh, Pennsylvania: RWS Publications; 2007. 